Севрук И.А., Писарев Д.И., Новиков О.О., Алексеева К.А., Малютина А.Ю.
ИССЛЕДОВАНИЕ СОСТАВА ЭФИРНОГО МАСЛА БАЗИЛИКА ОБЫКНОВЕННОГО - ОСIMUМ BASILICUM L. ФЛОРЫ БЕЛГОРОДСКОЙ ОБЛАСТИ

Севрук Инна Александровна, ассистент кафедры фармацевтической химии и фармакогнозии, Медицинского института, НИУ «БелГУ»

308015, г. Белгород, ул. Победы, 85, Россия

e-mail: sevruk@bsu.edu.ru

Писарев Дмитрий Иванович д.фарм.н, доцент кафедры фармацевтической химии и фармакогнозии, Медицинского института, НИУ «БелГУ»

308015, г. Белгород, ул. Победы, 85, Россия

e-mail: pisarev@bsu.edu.ru

Новиков Олег Олегович, д.фарм.н. заведующий кафедрой фармацевтической химии и фармакогнозии, Медицинского института, НИУ «БелГУ»

308015, г. Белгород, ул. Победы, 85, Россия

e-mail: novikov@bsu.edu.ru

Алексеева Ксения Александровна студентка Медицинского института НИУ «БелГУ» 308015, г. Белгород, ул. Победы, 85, Россия e-mail: 740890@bsu.edu.ru

Малютина Анастасия Юрьевна, к.фарм.н., стариий преподаватель кафедры фармацевтической химии и фармакогнозии, Медицинского института НИу «БелГУ»

308015, г. Белгород, ул. Победы, 85, Россия

e-mail: malyutina_a@bsu.edu.ru

\title{
Аннотация
}

$\mathrm{O}$ дним из перспективных для медицины растений является базилик обыкновенный - Ocimum basilicum L. B народной медицине трава O. basilicum L. используется в качестве отхаркивающего, противовоспалительного средства, гастритах, колитах, нефрите и др. Многочисленными исследованиями было установлено, что эфирное масло O. basilicum L. в эксперименте обладает хорошей антиоксидантной, противомикробной и цитостатической активностью. Методом газовой хроматографии - масс-спектрометрии определён химический состав эфирного масла в н-гексановом извлечении базилика обыкновенного O. basilicum L. произрастающего на территории Белгородской области. Установлено, что в его составе присутствует 11 компонентов, доминирующими из которых являются монотерпеновый спирт - $\beta$-линалоол, фенол - эвгенол и сесквитерпен - гермакрен D. Также в значительном количестве присутствует высокомолекулярный алифатический спирт - фитол. Изученный образец можно отнести к линалоол - эвгенольному типу. Эвгенол существенно преобладает в сумме, поэтому в дальнейшем стандартизацию сырья $O$. basilicum L. можно проводить в пересчёте на данный компонент.

$\mathrm{K}$ фия - масс-спектрометрия; эвгенол; линалоол. 
Sevruk I.A.,

Pisarev D.I.,

Novikov O.O.,

Alekseeva K.A.,

Malyutina A.Yu.

\section{INVESTIGATION OF OCIMUM BASILICUM L. ESSENTIAL OIL COMPOSITION OF THE FLORA OF BELGOROD REGION}

Sevruk Inna Aleksandrovna, Assistant Lecturer

Department of Pharmaceutical Chemistry and Pharmacognosy, The Institute of Medicine,

Belgorod State National Research University, 85 Pobedy St., Belgorod, 308015, Russia e-mail: sevruk@bsu.edu.ru

Pisarev Dmitry Ivanovich, Doctor of Pharmacy, Associate Professor

Department of Pharmaceutical Chemistry and Pharmacognosy, The Institute of Medicine,

Belgorod State National Research University, 85 Pobedy St., Belgorod, 308015, Russia e-mail: pisarev@bsu.edu.ru

Novikov Oleg Olegovich, Doctor of Pharmacy, Professor

Head of Department of Pharmaceutical Chemistry and Pharmacognosy, The Institute of Medicine,

Belgorod State National Research University, 85 Pobedy St., Belgorod, 308015, Russia e-mail:novikov@bsu.edu.ru

Alekseeva Kseniya Aleksandrovna, Student

The Institute of Medicine, Belgorod State National Research University, 85 Pobedy St., Belgorod, 308015, Russia e-mail: 740890@bsu.edu.ru

Malyutina Anastasiya Yurevna, PhD of Pharmacy Senior Lecturer

Department of Pharmaceutical Chemistry and Pharmacognosy, The Institute of Medicine,

Belgorod State National Research University, 85 Pobedy St., Belgorod, 308015, Russia e-mail: malyutina a@bsu.edu.ru

\section{Abstrakt}

$\mathrm{O}$ cimum basilicum $L$. is one of the most promising plants for medicine. The $O$. basilicum $L$. herb is used in folk medicine as an expectorant, anti-inflammatory agent, in gastritis, colitis, nephritis and other diseases. Numerous studies revealed that the O. basilicum L. essential oil in the experiment has a good antioxidant, antimicrobial and cytotoxic activity. The method of gas chromatography - mass spectrometry has determined the chemical composition of the essential oil in n-hexane extraction of $O$. basilicum $L$. growing on the territory of Belgorod Region. It was found that it contains 11 components, the dominant of which are monoterpene alcohol - $\beta$-linalool, phenol - eugenol and sesquiterpene - germakren D. Besides, it contains high molecular weight aliphatic alcohol - phytol in significant amounts. The studied sample can be attributed to linalool-eugenol type. Eugenol significantly predominates in the amount, so in the future the standardization of the O. basilicum L. raw material can be done in terms of this component.

K try; eugenol; linalool. 
Введение Пополнение ассортимента лекарственных препаратов на основе растительного сырья происходит в первую очередь в результате заимствования перспективных растений из народной медицины. Одним из таких растений является широко известный базилик обыкновенный - Ocimum basilicum L. В народной медицине трава $O$. basilicum L. используется в качестве отхаркивающего, противовоспалительного средства, гастритах, колитах, нефртие. Настой из листьев применяют при стоматите, неврозах, бронхиальной астме, снижении аппетита, крое того является эффективным лактогонным средством. Свежие и сухие листья используют в пищу в качестве приправы $[1,2]$.

Многочисленными исследованиями было установлено, что эфирное масло $O$. $b a-$ silicum L. в эксперименте обладает хорошей антиоксидантной активностью, например, что было продемонстрировано на торможении свободно-радикального окисления линолевой кислоты. Әфирное масло in vitro имеет широкую антибактериальную активность в отношении бактериальных штаммов: золотистого стафилококка, кишечной палочки и патогенных грибов родов: аспергилл, мукор, фузариум и др. [3,4]. Также у эфирного масла листьев O. basilicum L., выявлены противосудорожные свойства, а в ряде экспериментов in vitro показано цитотоксическое действие при ряде опухолей $[5,6]$.

Химический состав эфирного масла $O$. basilicum L. существенно варьирует в зависимости от места произрастания, сезона и погоды. Однако, американские исследователи установили, что O. basilicum L. образует 7 хемотипов по преобладанию тех или иных компонентов: линалооловый, линалоолово-эвгенольный, метилхавиколовый, метилхавикол-линалооловый, метилэвгенол-линалооловый, метилциннамат-линалооловый и бергамотановый. Наличие таких разнообразных хемотипов у $O$. basilicum L. обуславливает разный запах их эфирных масел [7].

Несмотря на широкое применение настоящего растения в народной медицине в научной медицине его до настоящего времени не используют по причине отсутствия нормативной документации.

Базовой процедурой при изучении любого растения является установление его химического состава, в ходе которого определяется компонентный состав, и выделяются маркерные соединения, определяющие фар- макологическую эффективность растения или характеризующие его подлинность, по которым в дальнейшем проводится стандартизация сырья. На основании аналитических исследований также делается заключение о безопасности растений по отсутствию токсичных компонентов.

O. basilicum L. относится к ароматическим растениям, следовательно, наиболее значимой группой действующих соединений являются летучие компоненты - эфирные масла и фенолы. Изучение компонентного состава терпенов указанного растения позволит выявить доминирующие соединения, по которым в дальнейшем можно будет проводить стандартизацию сырья.

Цель исследования - химическое изучение состава эфирного масла O. basilicum L.

Материалы и методы. Сырьё для эксперимента - надземную часть заготавливали на территории Белгородской области во время цветения в сухую погоду. Высушивали в тени в хорошо проветриваемом помещении и измельчали.

Для получения суммы терпенов из изучаемого растения был использован метод экстракции. Для этого 1,0 г воздушно-сухого сырья (травы) O. basilicum L. помещали в аппарат «Soxlet» и экстрагировали в течение 2-х часов н-гексаном. Полученное извлечение далее хроматографировали методом газо-жидкостной хроматографии с масс-спектрометрическим детектором.

Измерение проводили методом газовой хроматографии - масс-спектрометрии на приборе хромато-масс-спектрометр модели GCMS-QP2O1O Ultra, фирма-изготовитель «Shimadzu», Япония, регистрационный номер №46022-10. Тип средств измерений утверждён приказом Федерального агентства по техническому регулированию и метрологии от 28 декабря 2010 г. №5484.

Хромато-масс-спектрометр представляет собой настольную многоцелевую автоматизированную систему, состоящую из газового хроматографа модели GC-201o Plus, квадрупольного масс-спектрометра, форвакуумного насоса, персонального компьютера, специализированного программного обеспечения и дополнительных аксессуаров.

Источник ионов масс-спектрометра работает в режиме электронного удара. Разделение ионов осуществляется квадрупольным масс-фильтром, детектирование - вторич- 
ным электронным умножителем с обращённым динодом. Детектирование может быть проведено в режимах селективного ионного детектирования (SIM), или по полному ионному току $(S C A N)$ или в режиме одновременной регистрации $S I M / S C A N$.

Разделение проводили на колонке:

Zebron ZB-5MS $30 \mathrm{~mL} \times 0,25 \mathrm{~mm} \mathrm{ID} \times$ $o, 25 \mu m d f$

Жидкая фаза: 5\%-polysilarylene95polydimethylsiloxane;

Температурные пределы: от $-60 \mathrm{C}^{\circ}$ до $325 / 350 \mathrm{C}^{\circ}$;

Серийный номер № 238059.

Условия хроматографирования:

Газ-носитель - гелий с постоянным потоком - 0,7 мл/мин;

Анализ осуществлялся в режиме программируемых температур:
Температура колонки программировалась в диапазоне от $70 \mathrm{C}^{\circ}$ (изотерма 2 мин.) $230 \mathrm{C}^{\circ}$ (изотерма 5 минут). Скорость подъёма температуры $3 \mathrm{C}^{\circ}$ /мин

Температура испарителя - $240 \mathrm{C}^{\circ}$;

Температура ионного источника $-250 \mathrm{C}^{\circ}$;

Температура интерфейса - $250 \mathrm{C}^{\mathrm{o}}$;

Режим ввода пробы - с делением потока (Split ratio 1/50) - 1,5 мин;

Напряжение на детекторе - o,84 кB;

Поток эмиссии - $60 \mu \mathrm{A}$;

Объём вводимой пробы - $1 \mu \mathrm{l}$.

Детектирование осуществляли в режиме полного ионного тока (SCAN) в диапазоне $\mathrm{m} / \mathrm{z} 70$ - $350 \mathrm{Da}$, со скоростью сканирования 769 и результирующим временем 0,4 сек.

Время анализа - 60 минут.

Результаты исследования и их обсуждения. Результаты хроматографирования представлены на рисунке 1.

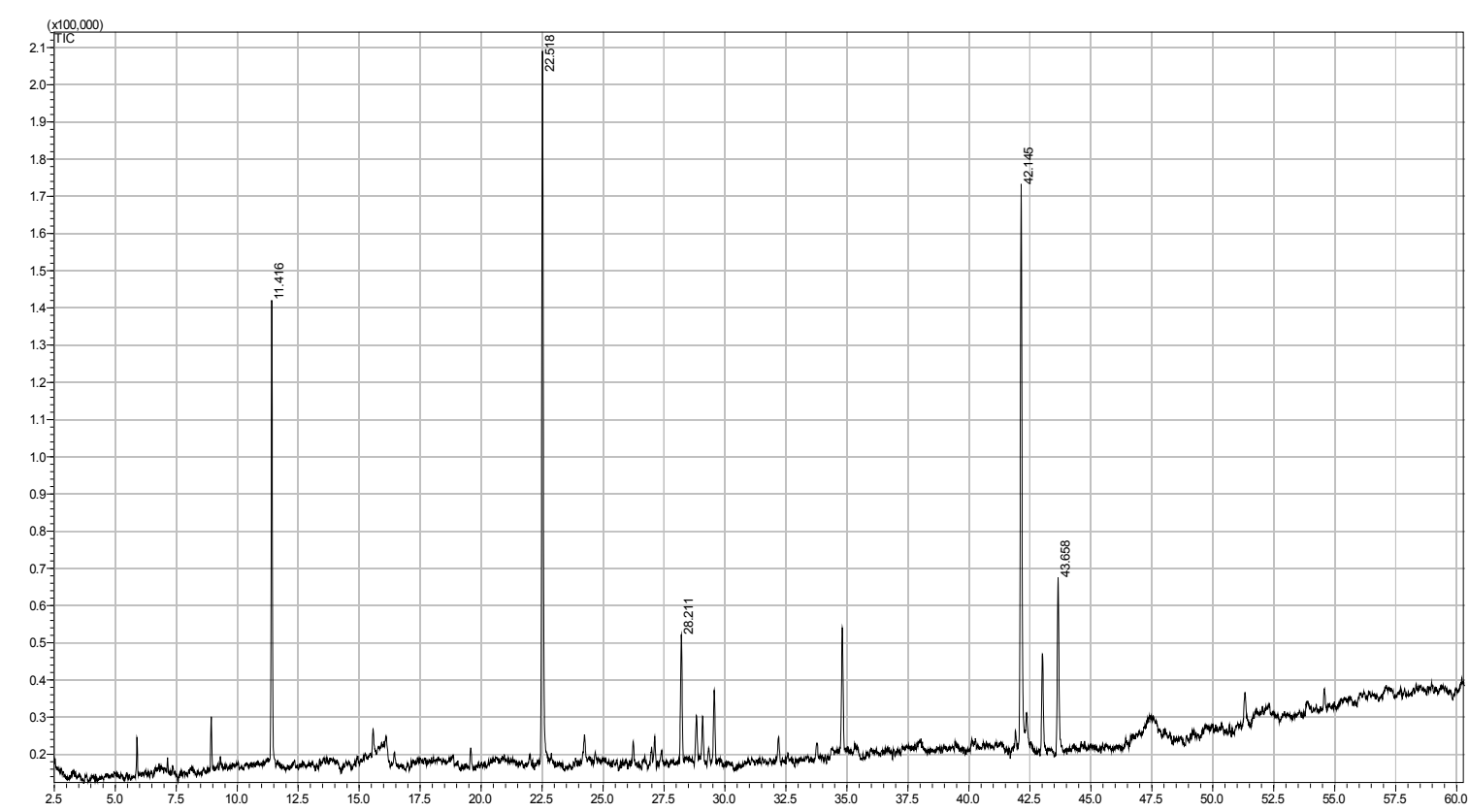

Рисунок .1 - Хроматограмма н-гексанового извлечения травы О. bаsilicum L. Figure 1. - The chromatogram of n-hexane extraction of the O. basilicum L. herb

Рассчитанные критерии хроматографических пиков представлены в таблице 1.

Таблица 1

\section{Критерии хроматографических пиков компонентного состава терпенов} O. basilicum $L$.

Table 1

Criteria of chromatographic peaks of the O. basilicum L. terpenes component composition

\begin{tabular}{|c|c|c|c|c|}
\hline No & Ret. time & $\mathbf{N}$ & Area, S & $\mathbf{T}_{\mathbf{f}}$ \\
\hline 1. & $\mathbf{1 1 . 4 1 6}$ & $\mathbf{2 1 2 1 8 8}$ & 396474 & $\mathbf{1 , 0 2 2}$ \\
\hline 2. & 22.518 & 520741 & 808007 & $\mathbf{1 , 0 4 3}$ \\
\hline 3. & 28.233 & 852948 & 134128 & 1,077 \\
\hline 4. & 42.167 & 1663620 & 672254 & $\mathbf{1 , 0 3 7}$ \\
\hline 5. & 43.687 & 1947579 & 187265 & $\mathbf{1 , 0 5 8}$ \\
\hline
\end{tabular}

Ret. time - абсолютное время удерживания, Area, S - площадь пика, $\mathrm{N}$ - число теоретических тарелок, $\mathrm{T}_{\mathrm{f}}$ - коэффициент асимметрии 
Расшифровку компонентного состава терпенов O. basilicum L. проводили с использованием библиотечной базы данных NIST 11.

Компонентный состав эфирного масла O. basilicum L. представлен в таблице 2.

Компонентньй состав әфирного масла O. basilicum L.

Таблица 2

The component composition of the O. basilicum L. essential oil

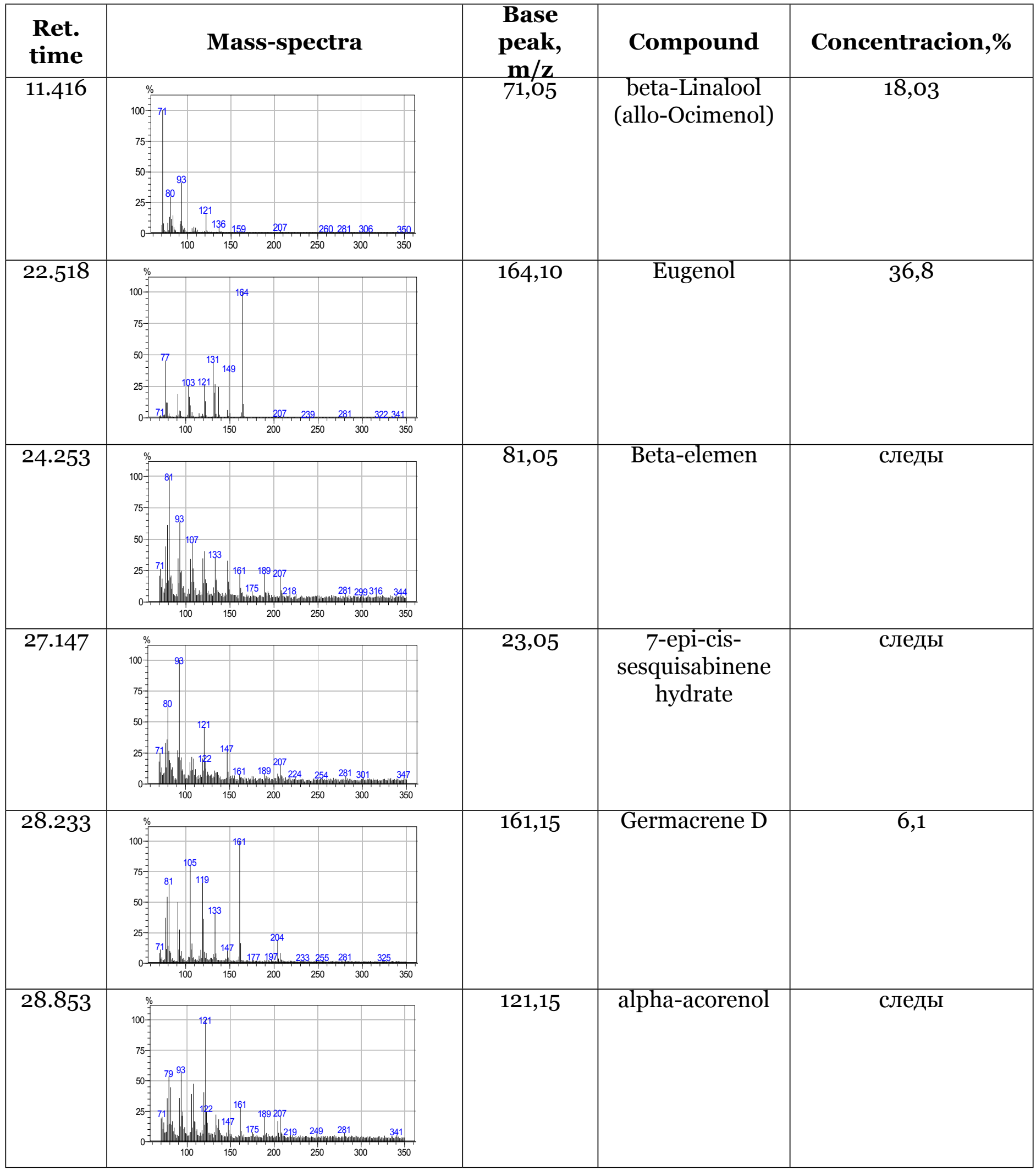




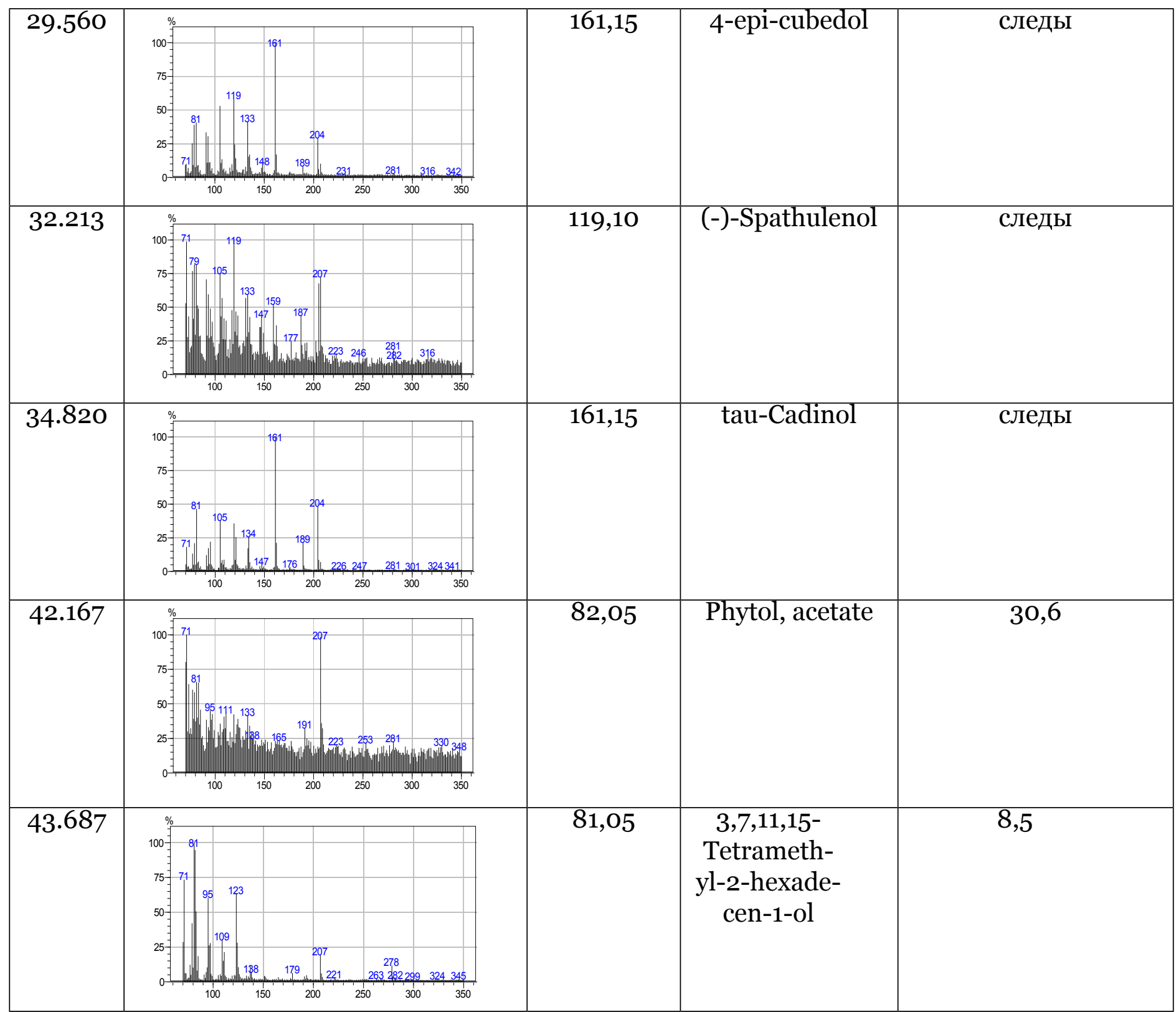

\section{Выводы:}

Данные таблицы 2 показывают, что в н-гексановом извлечении O. basilicum L. присутствуют 11 компонентов, доминирующими из которых являются монотерпеновый спирт - $\beta$-линалоол, фенол - эвгенол и сесквитерпен - гермакрен D. Kроме того в значительных количествах присутствуют высокомоле- кулярные алифатические спирты, а именно фитол. Поскольку доминирующими терпенами являются линалоол и эвгенол, то исследованный образец можно отнести к линалоол-эвгенольному типу. Эвгенол существенно преобладает в сумме, поэтому в дальнейшем стандартизацию сырья O. basilicum L. можно проводить в пересчёте на данный компонент. 


\section{ЛИТЕРАТУРА:}

1. Лавренёва Г.В., Лавренёв В.К. Полная энциклопедия лекарственных растений. Том 1. СПб. : Издательский дом «Нева»; М.: «ОЛМА-ПРЕСС», 1999. $736 \mathrm{c}$.

2. Соколов, С. Я. Фитотерапия и фитофармакология: Руководство для врачей. М.: Медицинское информационное агентство, 2000. 976 с.

3. Hussain A.I., Anwar F., Sheraz S.T.H. [et al.] Chemical composition, antioxidant and antimicrobial activities of basil (Ocimum basilicum) essential oils depends on seasonal variations. Food chemistry. 2008. Vol. 108, №3. P. 986-995.

4. Joshi R.K. Chemical composition and antimicrobial activity of the essential oil of Ocimum basilicum L. (sweet basil) from Western Ghats of North West Karnataka, India. Ancient Science of Life. 2014. Vol. 33, №3. P 151-156.
5. Kathirvel P., Ravi S. Chemical composition of the essential oil from basil (Ocimum basilicum Linn.) and its in vitro cytotoxicity against HeLa and HEp-2 human cancer cell lines and NIH $3 \mathrm{~T} 3$ mouse embryonic fibroblasts. Nat. Prod. Res. 2012. Vol. 26, №12. P. 1112-1118.

6. Oliveira J.S., Porto L.A., Estevam C.S. [et al.] Phytochemical screening and anticonvulsant property of Ocimum basilicum leaf essential oil. Plant Med. Aromat. 2009 Vol. 8. P. 195-202.

7. Zheljazkov V.D., Callahan A., Cantrell C.L. Yield and oil composition of 38 basil (Ocimum basilicum L.) accessions grown in Mississippi. J. Agric. Food Chem. 2008. Vol. 56, №1. P 241-245.

\section{REFERENCES:}

1. Lavrenyova G.V., Lavrenyov V.K. The Complete Encyclopedia of Medicinal Plants. Volume 1. St. Petersburg. Publishing house "Neva"; M .: "Olma-Press", 1999. 736 p.

2. Sokolov S.Ya. Phytopharmacology and Phytotherapy: A Guide for Physicians. M.: Medical Information Agency, 2000. 976 p.

3. Hussain A.I., Anwar F., Sheraz S.T.H. [et al.] Chemical composition, antioxidant and antimicrobial activities of basil (Ocimum basilicum) essential oils depends on seasonal variations. Food chemistry. 2008. Vol. 108, №3. P. 986-995.

4. Joshi R.K. Chemical composition and antimicrobial activity of the essential oil of Ocimum basilicum L. (sweet basil) from Western Ghats of North West Karnataka, India. Ancient Science of Life. 2014. Vol. 33, №3. P 151-156.
5. Kathirvel P., Ravi S. Chemical composition of the essential oil from basil (Ocimum basilicum Linn.) and its in vitro cytotoxicity against HeLa and HEp-2 human cancer cell lines and NIH $3 \mathrm{~T}_{3}$ mouse embryonic fibroblasts. Nat. Prod. Res. 2012. Vol. 26, №12. P. 1112-1118.

6. Oliveira J.S., Porto L.A., Estevam C.S. [et al.] Phytochemical screening and anticonvulsant property of Ocimum basilicum leaf essential oil. Plant Med. Aromat. 2009 Vol. 8. P. 195202.

7. Zheljazkov V.D., Callahan A., Cantrell C.L. Yield and oil composition of 38 basil (Ocimum basilicum L.) accessions grown in Mississippi. J. Agric. Food Chem. 2008. Vol. 56, №1. P 241-245. 